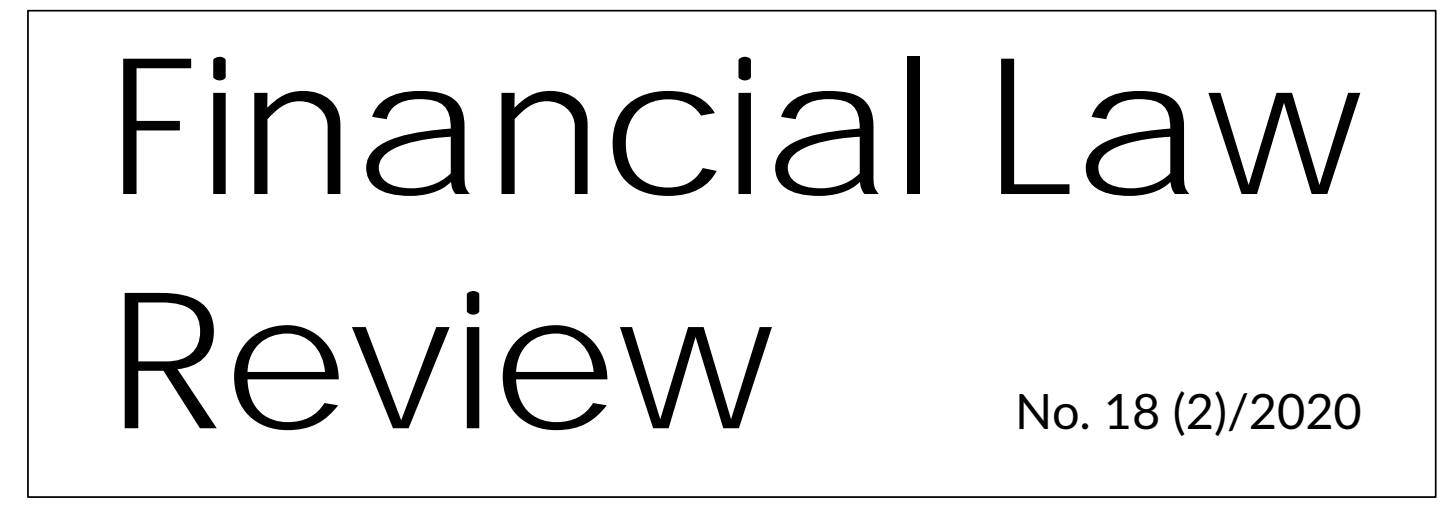

UNIVERSITY OF GDAŃSK • MASARYK UNIVERSITY • PAVEL JOZEF ŠAFÁRIK UNIVERSITY • UNIVERSITY OF VORONEZH http://www.ejournals.eu/FLR

\title{
SZYMON OBUCHOWSKI* \\ INCOMPLETELY THEORIZED AGREEMENTS AND THEIR SIGNIFICANCE FOR TAX LAW-MAKING
}

\begin{abstract}
This contribution introduces the idea of incompletely theorized agreements conceived by American legal theorist Cass R. Sunstein to the doctrine of tax law. The main aim of the contribution is to describe the content and nature of the idea in by presenting the ways in which it may be seen as coherent with empirical reality and how to assess its connection to it. The paper also draws several conclusions that can be made by juxtaposing the idea with the process and issues of tax law-making in divided society with examples drawn from Polish practice. What follows is the prescription to keep the discussion concerning tax law amendments as disconnected from political practice in divided society as possible, in order to maintain tax law quality and efficiency. It should be practically oriented and focusing on outcomes of projected legislative actions that are possible to predict. The methods used in the article are mainly description, discussion compiling and reshaping of theoretical ideas, rhetorical justification and grounding of drawn conclusions.
\end{abstract}

Key words: Incompletely theorized agreements, democratic discourse, law, financial law, application of financial law, financial law-making

JEL Classification: K10, K400

*PhD, Assistant in Department of Financial Law, Faculty of Law and Administration, University of Gdańsk, Poland. Author specializes in tax law and its combining with theory and philosophy of law. Contact email: szymon.obuchowski@prawo.ug.edu.pl, https://orcid.org/0000-0002-5033-9980. 


\section{Introduction}

This article aims to present and acquaint the tax law doctrine with the idea of "incompletely theorized agreements" (hereinafter: "ITA") devised by Cass R. Sunstein [Sunstein 1994, 1995, 1996, 2001]. Since its first publication, the idea incurred a debate concerning the vision of judicial reasoning and application of law, mainly in American legal theory (see section 2.5), which revolved around and within the dichotomy of "theoryembedded" and "practically oriented" approaches [Dworkin 1997: 354]. In its original formulation, the idea indeed concerns mainly judicial reasoning, but from the very beginning Sunstein suggests that it can be seen as a description of a variety of activities present in democratic society [Sunstein 1994: 141-144]. Hence, the idea is partly of political nature. Further than mere introduction and description of its content, this contribution aims to collate it with problems of tax law-making, illustrated by examples of polish practice. The goal is to draw conclusions from the idea, which would be specific to tax legislation field.

Along with formulating several proposals to be taken into consideration by the legislator and participants of the legislative process, the article examines the nature of the idea and describes how in effect the aforementioned proposals should be interpreted.

Since the methods utilized by the originator of ITA's were mostly the ones specific to political sciences, philosophy and theory of law, the same methods will be used in the paper. Among others, these are especially methods such as conceptual and axiological analysis, philosophical and theoretical deliberations combined with logic, which all fall into the broader category of rhetoric, as a method typically used in humanities [Raymond 1982]. Accordingly, in my view, it is not possible to speak, in the sense of experimental sciences, of "hypothesis" to be confirmed or disproved by the paper. More accurately it can be stated that it proposes a thesis, that through the use of Sunstein's ITA idea a fragment of social practices composing the process of tax law-making can be demonstrated from previously unseen angle. Such a thesis can only be more or less accurately grounded by justification laid down in reasoning behind it, and this is a factor at least in some degree assessed subjectively. Since these issues are of vital importance to the subject matter of the paper, they are also covered. 
2. The basic characteristics and origin of the idea of 'Incompletely Theorized Agreements'

Sunstein's idea of "incompletely theorized agreements" was formulated partly as a description aimed at elucidating "legally" pressing phenomena, especially important in the field of constitutional law. Its content and importance goes beyond legal themes only and could be seen as instructive in any area in which collective course of action and essential decisions have to be determined in more or less deliberative, as well as cooperative and multilaterally agreed fashion. Using Sunstein's terminology, it can be said that the idea is accurate not only for "democratic practice", but for all fields of social life which depend on "cooperative practice". It could be also argued that every specific branch of law has its roots immersed in regulations on constitutional level, therefore conceptions dealing with its subject matter likewise "radiate" onto lower levels of legal system and its contents.

The idea of ITA was first proposed by Sunstein in 1994 as a part of Tanner Lectures on Human Values he gave in autumn of that year at Harvard University [Sunstein 1994]. Since it sparked interest from legal scholars at once, a commentary followed in 1995 [Sunstein 1995]. Since then, the idea was reprised and refined in several publications [Sunstein 1996 2001], but its core remained unchanged.

\subsection{Incompletely Theorized Agreements and Group Polarization - Definitions}

Sunstein observes that liberal democratic regimes which rely on decisions and politics introduced and devised by collective bodies through public deliberation and discussion, and which by their nature have to be accepted and respected by a society of citizens equal by law, face an intense difficulty in form of "deliberative trouble" [Sunstein 2001: 13-48]. It takes shape of phenomena that he dubbed as "group polarization", stemming from practise of "enclave deliberation", which is further strengthened by "cascade effects". In short, "group polarization" is a situation in which "members of a deliberating group predictably move toward a more extreme point in the direction indicated by the members' predeliberation tendencies" [Sunstein 2001: 15]. As Sunstein observes, its potentially dangerous influence may take shape of: "danger to social stability, a source of social fragmentation, and a safeguard against social injustice and unreasonableness" [Sunstein 2001: 15-16]. "Cascade effects" that strengthen the intensity and scope of group polarization are social influences stemming from reputational and informational factors that shape the attitudes of agents taking part in public discussion [Sunstein 2001: 16-22]. 
Dangers connected with group polarization lead to the thesis that deliberative trouble, mostly due to group polarization, may cause infringements to the stability of a democratic regime and hamper its proper functioning, to the point in which it paralyzes its ability to deal with elementary problems and tasks - such as devising a complete constitution in written form, as in the case of Israel [Sunstein 2001: 50]. The idea of ITA was devised by Sunstein as an answer and remedy for some of these problems. In its core it indicates that it is possible for a large group of people all of whom have a say on particular matter and power to decide in that aspect, to reach an agreement on the sought solution without reaching an agreement on the basis in which it is grounded. In other words, they may rationalize it in entirely different manner, thus having their own reasons for saying "yes", while still agreeing on a given decision. In that way it is possible for society to "solve problems" and for constitutional orders - to function. The use of ITA "enlists silence on certain basic questions" due to variety of possible reasons, such as persisting disagreement, uncertainty, limits of time and capacity, and heterogeneity of discussants. Therefore it is possible to discuss and reach consensus on pressing matters without connecting them to answers for questions of basic nature, which would require to design a "general theory" [Sunstein 2001: 50].

\subsection{The Role of Incompletely Theorized Agreements in Law-making}

Examples of ITA can be found in constitutional (and lower level) provisions of all existing democracies. Stipulation of general principles such as "freedom of speech" in written constitutions of eastern European countries was, according to Sunstein, possible only because they were "incompletely specified". Their societies agreed on "abstract provisions" without bringing the discussion about "what they really entail" to an end because of inability to do so in reasonable time limit. Actual, practical content of these abstractions is left to be determined in concrete cases by judges [Sunstein 2001: 56]. In these situations the audience is significantly smaller and power to decide on legal force and meaning of the provisions is fairly centralized.

Sunstein describes two more classes of situations in which ITA's appear by distinguishing three "levels" of principles agreed upon ${ }^{1}$. Situation described above is an incompletely theorized agreement concerning "high-level" principles, and "incomplete theorization" in

\footnotetext{
1 "Principles" are understood here as "provisions guiding legally obliged conduct in regard to a given matter".
} 
that case consists of temporarily abstaining from precising what kind of conduct is legally obliged from subjects who have to refrain from infringing "freedom of speech". Second kind of situations consist of agreeing on "mid-level" principles, when part of the provision which rather clearly guides its application is specified, but there is no agreement why it is in force and it still leaves certain freedom on deciding concrete cases ${ }^{2}$. Thirdly, incomplete theorized agreements may exist only in regard of class of particular outomes, clearly stemming from "low-level" principles guiding the need of their occurence, without consent on any higher part of their foundation. What is specific for these is that they elude connection to specific "general" theory and may be ascribed to various doctrines of entirely different nature [Sunstein 2001: 57].

Sunstein's observation concerning high-level principles ("much lawmaking (...) becomes possible only because of this phenomenon") [Sunstein 2001: 56] holds true for other two classes as well. Prevalence of ITA's shows their indispensability in law-making and underline the compromise character of the process in democratic countries.

It must be noted that the classification from above is only an organising convention, not a fully specified claim about existence of three completely separate classes. Sunstein himself stipulates that "there is no algorithm" that would make it possible to distinguish principles of any of the levels [Sunstein 2001: 57]. The difference between them is a matter of degree.

\subsection{The Nature, Methodology and Measure of the Scientific Merit of the Idea}

Describing the occurrences of ITA's in social reality, Sunstein puts forward an observation which is logical and empirical at the same time, according to which "any rationale-any reason-is by definition more abstract than the result it supports" [Sunstein 2001: 51]. What follows as a consequence is another remark, according to which it is possible that people agree on correct prediction in regard of a given causal relationship without knowing why it is accurate. Even further - leaving probability aside - they may know that something is true without knowing why it is so. Sunstein relates these observations to factual and normative sphere alike [Sunstein 2001: 52]. If delimitation of these two is

\footnotetext{
2 Sunstein gives a following example concerning freedom of speech: "People may think that government may not regulate speech unless it can show a clear and present danger-but disagree about whether the basis for this principle (e.g., whether it is founded in utilitarian or Kantian considerations) and disagree too about whether the principle allows government to regulate a particular speech by members of a fascist political party" [Sunstein 2001: 57].
} 
applied $^{3}$, they may by further specified by stating that it is possible for people to agree that something is true without knowing why it is so as well as agreeing that something ought to be without being able to tell why it should be so. This is possible by performing "conceptual descent", which consists of shifting discussion towards lower level of abstraction [Sunstein 2001: 51].

Up to that point, the idea of incompletely theorized agreements may be labelled as "descriptive", meaning that it is a set of observations about phenomena that occur in social reality. But, as its Author himself puts it, its descriptive character is only "partial" (Sunstein 2001: 52). The rest of its content is of normative character, as it contains prescriptions addressed to legislators and judges.

The descriptive character of the ITA idea has to be examined more closely and thus clarified. According to delimitation mentioned above, if ITA idea is partly descriptive, therefore it should contain set of statements regarding facts that are possible to test against reality, in order to tell whether it is true. Typically it is done by describing an experiment or other form of examination through which it is possible to prove or falsify its truth. In it should possible to tell if ITA's exist by pointing at situations that fulfil their characteristics.

Sunstein does not describe any forms of examination that could determine whether ITA's really occur in social reality. The reason for this shortage is that "descriptive character" of the idea is of other nature than it would be if it was a part of sciences. In humanities, "description" is laid down differently, because they typically concern much broader phenomena than empirical sciences ${ }^{4}$. Therefore it is not possible to test their truth in any conceivable way. Such undertakings would be way beyond current technical possibilities or would involve efforts extremely disproportionate to the amount of knowledge possible to gain. Because of that, "proving" a thesis in humanities consists of using rhetorical methods in order to back them with description cogent enough to convince the addressees about its cohesion with empirical reality. It is a method that allows less certainty than experiments conducted in sciences, but enables to conduct inquiries of broader range ${ }^{5}$ [Raymond 1982: 780-783].

\footnotetext{
${ }^{3}$ By agreeing that factual sphere is described by descriptive statements which inform what is and what is not, and normative sphere consists of statements of what ought to be and what not. There is no logical way to infer one kind of these statements from another [Obuchowski 2018: 85-86].

${ }^{4}$ Compare: how to design a social policy vs pinpointing the exact mass of Higgs Boson.

${ }^{5}$ For similar observations regarding dependencies of finance and financial law, see [PiotrowskaMarczak 2018: 152-153].
} 
What further follows from this type of "descriptive" nature of the idea is the fact, that the phenomena it describes may be as well portrayed in various ways, all of which may be seen as "true" (assuming that "truth" means "properly and convincingly explained" here). Social occurrences counted as ITA's may very well be named differently and cited as examples of some other phenomena described by some other notion, which, if motivated sufficiently, could also be a part of "true" description.

Reasoning along these lines is a part of broader philosophical stance known as "constructivism". Among philosophical doctrines developed in this spirit one of particularly illuminating examples is philosophy of Nelson Goodman. In central book on the topic he laid down the idea of "worldmaking", according to which, even if "objective reality" exists, it is imperceptible without a system of predicates which structure perceived data [Goodman 1978]. This system contains notions describing all phenomena isolated within total experience data as conceptual entities. Isolating these is in fact an act of creation, because only human conceptual decision stands behind our conviction about existence of certain things (even objects of material world ${ }^{6}$ ). Hence the name of "worldmaking". Experience data may be arranged in countless, completely different, yet still intelligible and logical ways. In scientific efforts it is typically done in form of theories, notions and definitions connected with each other. Since all of them can be "true", Goodman suggests to compare theories with each other in terms of their "efficacy in worldmaking and understanding", because "for a categorial system what needs to be shown is not that it is true but what it can do" [Goodman 1978: 129].

This leads to a following conclusion: value of Sunstein idea of ITA's is determined by its ability to describe reality in insightful way, which manifests itself in describing important aspects of certain social phenomena in manner previously unnoticed. That value is assessed partly subjectively. Assessment of descriptive part of ITA's idea directly affects the perceived level of validity of its normative content.

This observation is strengthened by two critical reviews of Sunstein's 1996 book in which he laid out the ITA's idea comprehensively for the first time. Edward L. Rubin points out

\footnotetext{
${ }^{6}$ The passage about "starmaking" explains the idea accurately: "(...) how we can have made anything older than we are? Plainly, by making a space and time that contains those stars. By means of science, that world (and many another) was made with great difficulty and is, like the several worlds of phenomena that also contain stars, a more or less right or real world. We can make the sun stand still, not in the manner of Joshua but in the manner of Bruno. We make a star as we make a constellation, by putting its parts together and marking off its boundaries.

In short, we do not make stars as we make bricks; not all making is a matter of molding mud. The worldmaking mainly in question here is making not with hands but with minds, or rather with languages or other symbol systems (...)." [Goodman 1996: 145].
} 
that due to lack of pertaining to empirical reality ("What judge or legislature in America has ever attempted a completely theorized justification for a particular decision?"), Sunstein's remarks about ITA should be seen as targeted to legal scholars. He also reproaches that Sunstein did not "locate his discussion in intellectual context" [Rubin 1997: 275]. The shortcoming is especially prominent in his methodology - Rubin's main argument against Sunstein is that he correctly envisioned courts and judges as institutions and studied them in this view, but lingered with research methods by omitting "microanalytic perspective", which would be particularly insightful (Rubin 1997: 281-286). By listing possible fields of more detailed enquiry ${ }^{7}$ he does nothing else than questioning empirical foundations of Sunstein's normative prescriptions.

Scott J. Saphiro goes even further along these lines. He challenges foundations of Sunstein's idea ${ }^{8}$ to conclude that his claims about origins of ITA's in legal practice are false. By offering entirely different explanation of lack of theorizing in judicial reasoning, he claims that theories are seldom relevant for adjudication [Saphiro 1997: 399]. He also observes that legal reasoning does not stand out of other types of reasoning where ITA's also appear, due to the fact that scholars rarely question the paradigm under which they operate. Theories are invoked when basic questions arise, alike in sciences and legal reasoning, and that kind of discourse is a sign of "confusion or revolution within the research community" [Saphiro 1997: 401-402]. In adjudication, the losing side has to be persuaded that its stance was to be dismissed. Theory could be of use if the basic legal methods of reasoning are questioned - and that hardly ever is done in earnest [Saphiro 1997: 400-401, 403]. Saphiro challenges Sunstein's assumption that theory is omitted because in most cases it's relevant but would rise controversies, by asserting that it is omitted mostly because it is irrelevant and there are no controversies [Saphiro 1997: 403]. This way, he aims to topple the normative content of ITA's idea completely. What is distinctive in his argumentation is the sameness - with Sunstein's description - of its nature. It is in every way as rhetorical, and the reader has to decide by himself which one is more persuasive to him.

\footnotetext{
${ }^{7}$ He mentions ie. personal motivations of judges who make decisions, examination of ways in which information for decision making is collected and processed, relations of courts to other institutions and their mutual influences [Rubin 1997: 282-284].

8 Saphiro battles "historical claim" required for justification of ITA's idea origins explanation, according to which homogeneity of society should lead to less theorizing, by offering empirical evidence that it is exactly the opposite [Saphiro 1997: 397-398]. He also points that ITA's cannot be an answer for pluralism in the society because people have articulated enough views only in the field of public law. In private law situations in which their opinions matter are much more scarce, but ITA's nonetheless appear. Therefore the reason for their existence must be something else than ideological plurality [Saphiro 1997: 395].
} 


\subsection{Normative Content of the Idea}

The normative content of the ITA idea may be summed up as follows:

"in certain situations and in regard of certain topics of legal nature, settling with ITA instead of further, more profound debate is socially beneficial for variety of reasons; therefore discussions in these cases should head for an ITA instead of theory-based discourse from the beginning".

The remaining of the "normative part" of the idea is designed to back this prescription with arguments of empirical, yet only rhetorically justified nature.

Sunstein characterizes ITA's as part of a set of "special virtues to avoiding large-scale theoretical conflicts", by ascribing them a "central role in the constitution of a democratic social order" [Sunstein 2001: 52]. They enable "constructive uses of silence" and thus allow discussants to postpone concluding certain topics until they are ready to participate in agreeable compromise on the matter. Incompleteness in such a case is a result of choosing only these points for further discussion (with agreement in sight) upon which it can be constructively concluded. This does not mean that matters left aside are less important, but the inability of reaching an agreement loses its obstructive character. As Sunstein remarks, "what is said and resolved is no more important than what is left out" [Sunstein 2001: 59]. The capacity to recognize the inability to form a fully-developed theory in the area discussed may be also seen as a sign of rational modesty.

Through omissions of this kind, it is possible to promote social stability and contain disagreement on fundamental matters. Left aside for a time being, these topics contribute less to group polarization and do not fuel cascade effects that strengthen it on occasions where consensus is needed and eventual discussion may reach very heights of beliefs and world views of opposing groups. This way, ITA's enable "a common way of life without producing unnecessary antagonism". As Sunstein observes, retracting from challenging opposing beliefs can be seen as a sign of respect for adherent, because it is a way of demonstrating a regard for the sole fact of him having a developed stance [Sunstein 2001: 59].

Another advantage resulting from putting discussion about fundamental matters on hold and settling with ITA is that debate may be concluded without causing a feeling of defeat for any of the discussants. Since consensus is reached on practical level, where it is needed, everyone involved may stay true to their beliefs in higher domain. As Sunstein 
observes, "they lose a decision but not the world (...). When the authoritative rationale for the result is disconnected from abstract theories of the good or the right, the losers can submit to legal obligations, even if reluctantly, without being forced to renounce their largest ideals" [Sunstein 2001: 60].

Sunstein also argues that reaching "theoretical end-state" in certain matter might suppress further public discussion the area, thus petrifying the possibility to produce social change. If such a theory existed, its presence would count as an overwhelmingly strong argument against reopening the debate on the matter it concerns. ITA's, meanwhile, "allow a large degree of openness" [Sunstein 2001: 60]. By settling only on the fact, that a set of ideas known by names, such as "freedom of speech" are important, but without declaring what exactly they entail, they allow and shape the field of further debate directed at their specific content. The awareness of the fact that discussion is not concluded, and for pragmatical reasons settled only partially should stimulate these who are convinced that they may move it forward to do so in due time.

\subsection{Reception of the Idea}

After its first presentation in 1994, Sunstein's idea received much attention from scholars, mostly from the representatives of American legal theory. It has become popular in other areas of research, and cited as part of an argument made in altogether different fields of sciences and humanities [Ruger 2007; Verma 2011; Schroeder 2012].

In the field of legal theory, the responses concentrated on the suitability of Sunstein's idea and particularly its aforementioned normative proposition as a theory of judicial reasoning, considering and testing it on various grounds. Despite universal applicability of the ITA idea, Sunstein's book introducing it in fully-fledged form (Sunstein 1996) concentrated precisely on that topic, hence the prevailing topic of the discussions the idea evoked. The responses, commenting on ITA as a theory of judicial reasoning, ranged from more [George 1997; Stone 1998] or less [Rubin 1997] appreciative to more [Dworkin 1996; Saphiro 1997; Alexander 1997; Bathaee 2007] or less [Duxbury 1997] critical.

One of the examples of critical analysis of Sunstein's idea came from Ronald Dworkin. He counted Sunstein among representatives of "practical approach" to legal reasoning, which he criticized as "impractical", as opposed to "theory-embedded" approach he advocated [Dworkin 1997: 354-355]. 
Dworkin reads Sunstein idea as a conjunction of three "incompleteness theorems", regarding: coordination, exposition of reasons and responsibilities of individual judgement in respect to joint judicial decision. He agrees with the first two - that it is beneficial to work with people favouring the same effects as we do despite different grounds for the preferences (he sees the proposition as an example of Rawls conception of "overlapping consensus") and that compromise is "wise in preparing a joint public accounting for an official decision" [Dworkin 1997: 369-370].

The third one is the one he finds unconvincing in the light of his remark about "constant threat of justificatory ascent" [Dworkin 1997: 356-357]. Justificatory ascent is a concept marking the situation in which a lower-level claim is questioned in discussion by reference to a claim from higher level of abstraction. Since both parties are interested in asserting their point, they may as well refer to even higher level claim in response - ad infinitum. Additionally, each claim may be contested on its according level before proceeding to the next one. As Dworkin points out, "there is no a priori or wholesale test for deciding when it will be required" [Dworkin 1997: 358]. The same holds true for the scope of the ascent [Dworkin 1997: 370-371]. Ascent's boundaries are shaped by the character of the inquiry. On these grounds Dworkin criticizes the idea of a constraint enforced on the discussants overhand [Dworkin 1997: 372]. Ultimately he reconciles Sunstein's position with his own as a call for "theoretical modesty", which can be paraphrased as a recommendation "that judges ascend to more abstract theory only when they have special reason to do so" 9 [Dworkin 1997: 373]. It is possible because Sunstein, as a matter of fact, does not stiffen his modesty prescription to the point of disavowing all theory in judicial reasoning a priori and concedes that "some cases cannot be decided at all without introducing a fair amount in the way of theory. (...) The claims on behalf of incompletely theorized agreements are presumptive rather than conclusive" [Sunstein 1996: 54]. His stance is that theory may be inadmissible on several classes of occasions, and that through manifesting theoretical modesty, which can be seen as a practical "virtue", there are important gains to be made.

Dworkins critique holds true also for law-making debate. There, alike, can be no limits of justificatory ascent for the projected legislator decision, the enquiry conducted and the discussion held. The debate should be conducted in the spirit of theoretical modesty in some cases, even to the extent of making it a secondary target of the whole project with

\footnotetext{
${ }^{9}$ However, they differ on what that "special reason" is. Sunstein holds that it is the certainty about the rightness of the theory, Dworkin - the opposite [Dworkin 1997: 374].
} 
benefits of ITA in sight, but the need for the justificatory - and theoretical as well - ascent cannot be excluded a priori.

Another voice of criticism along similar lines comes from Neil Duxbury. He indicates couple of difficulties which could arise if ITA's normative part was to be followed. Duxbury points at troubles with discerning levels of abstraction in certain cases. He uses the example of the question which claim is more abstract than another - about reprehensibility of abortion or murder? [Duxbury 1997: 166]. He further observes that monistic (in the sense of Isaiah's Berlin "hedgehog"10) theories of right and wrong surely are imperfect, but Sunstein's ITA's are not presented in such a form that would allow to view them as better alternative that would justify abandonment of the former [Duxbury 1997: 172-173]. Duxbury holds that it would allow the decision-makers to shun from their duty to weigh the matter thoroughly [Duxbury 1997: 173]. Ultimately he backs the call for theoretical modesty in similar way to Dworkin [Duxbury 1997: 174]. The same can be said about Yavar Bathaee [Bathaee 2007: 1485-1488].

Scholars favourable to Sunstein's position generally agree with the critics about call for theoretical modesty as its most important and plausible consequence. It is sometimes difficult to draw the clear line between endorsing and criticizing Sunstein's view - for example Adrienne Stone points out, as do critics, that Sunstein "has not completely established" arguments for general preference of ITA, but his account is plausible enough for her to be seen as an important backing for theoretical modesty [Stone 1998: 200-201]. Her endorsement comes in form of making use of the idea for analysing Australian High Court's decision-making [Stone 1998: 201-205]. Similarly Robert P. George sees a call for modesty as an asset of Sunstein's theory which he cites "as something of an antidote to the tendency of judges to treat themselves - and, even more importantly, for other actors in the political system (including citizens) to treat them - as enjoying supremacy in matters of constitutional interpretation" [George 1997: 1404].

In the iteration which serves as a basis of ITA's idea account in this paper, Sunstein acknowledges most of the objections. He concedes that the value of social stability and consensus is not an ultimate one and sometimes it may be more socially beneficial to reject the temporary calm offered by achievable ITA. Unjust social settings should be questioned despite the alluring charm of consensus [Sunstein 2001: 64-65]. That resonates with the

10 The "fox", contrary to the "hedgehog", does not seek an all-embracing single principle around which he organizes his worldview. For the origin of this methapor see [Berlin 2013: 1-2]; its use in theory of law - ie. [Dworkin 2011: 1-2]. 
acknowledgement that ITA's may be unjust, weak or unreliable themselves [Sunstein 2001: 61]. Therefore theories - if conditions for conceptual ascent arise - should also find their place in legal practice. They may be used as a foundation against which low-level ITA's can be tested (even if only through "thought experiments"), when confronted with more complicated backgrounds [Sunstein 2001: 65]. Sunstein also does not deny that there may exist good enough broad theory to make ITA's dispensable, and that usage of theory may produce consensus despite the difficulties of discussion. Ultimately he calls for modesty in the field of theory and in use of ITA's as well [Sunstein 2001: 65-66].

\section{ITA as a Foundation of Tax}

What strikes as first observation when adapting ITA's idea to tax law is the fact that the very institution of tax may be seen as based on incompletely theorized agreement. Hardly any serious political theory, and almost no state theory omits the topic of taxation (with possible exceptions of utopian ones, like communism or anarchism). It is a topic enduring in political theories since the very beginning of thought about and organization of public institutions. Hence, the institution of tax cannot be in any way seen as a result or fragment of results of implementing single high-level theory, because countless theories regarding the same matter and of similar kind include its usage. Taxes may "borrow" justification from higher theory if it prevails in society and its institutions, but this rarely occurs. Even if it does, there are always other variants of justifications available ${ }^{11}$. Therefore, it may be asserted that taxes are present in too many high-level theories for it to be possible to ever theorize them completely.

General concept of tax may be seen at best as a mid-level theory which fits in large set of two other types of higher level theories. These can be, however crudely, divided amongst two kinds - "state organization" theories and "political" theories. Political theories are the ones that may be the source of pursued politics, like christian democracy or socialism, in a state arranged in accordance to state organization theory, like liberal-democratic rule of law. Justification of existence of the tax according to the former is of "technical" kind, and

${ }^{11}$ Periods in which such situations took place do not invoke positive associations - what comes to mind are totalitarian regimes introducing "the one and only" valid political theory with help of propaganda and other forms of coercion. Even in instances like that it was impossible to conceal the fact that regimes of other kinds (ie. "capitalistic" in optics of communist countries) used the very same institution of tax with completely different justification and to meet other ends. This placed communist institutions in unfavourable (from regime's point of view) light and it therefore forced scholars to look for possible, "revolutionarily plausible" explanations, ie. about "the same [legislative] technique, but different substance" [Ostrowski 1970: 142]. 
according to the latter - of "substantial" kind, especially by providing means for which tax revenue is to be collected and spent ${ }^{12}$. What follows, is that large number of high-level political theories potentially justify the existence of taxes.

If society is pluralistic at least politically, it may be assumed that in any given country, the existing tax system's components may be justified differently according to the political views (high-level theories) fostered by existing social groups. It is also safe to assume that today's democratic countries, even if are mono-ethnic, like the Central Europe ones, are pluralistic politically. Therefore it may be asserted that taxes existing in democratic countries rest on ITA's.

\section{Specifics and Importance of the ITA's Behind Existing Taxes}

The main virtue of ITA's is their ability to soothe conflicts and create bridges over existing divisions in society. It applies also in the field of tax law. Without doubt, tax law-making, as Sunstein puts it, "becomes possible only because" of ITA's.

The nature of taxes - their redistributive function and ownership-infringing character contribute to their potential to incur social unrest [Gomułowicz 2013: 47-48]. That makes it plausible to say that the role of consensus regarding taxation is of extreme social importance, also when compared to other branches of law. The judicial and administrative practice and the phenomena of tax compliance motivated by trust [Scholz 1998] give evidence to the existence of that connection.

The importance of ITA's standing behind existing taxes can be underscored from at least two points of view. Firstly, falling acceptance for existing ITA's may affect fiscal efficiency of existing regulations by reducing trust in tax law and tax compliance, thus causing revenue to shrink. Furthermore, taxes do not operate in social vacuum. Conflicts from other public spheres penetrate debate concerning tax law legislation and application and vice versa - conflicts incurred by falling acceptance of ITA's in field of taxation may further perpetuate the strife "outside". Both are detrimental to social interests in broad sense. Damages caused by these dependencies are larger if in a given society group polarization already exists. And stronger it is, greater the extent of their reciprocal reinforcement.

\footnotetext{
12 The distinction is aimed at indicating that in a state organized in accordance to the former many of the latter may still exist amongst different social groups.
} 
It may be therefore argued that in democratic countries ITA's role in tax law is of immense importance. This supports not only Sunstein's call for theoretical modesty with regard to discussions about planned amendments, but also gives strong reasons for necessity of looking after existing "tax law ITA's" - the taxes that society managed to agree upon. The normative content of Sunstein's idea provides possibility for examination of methods in which they may be perpetuated.

\section{How to Maintain Tax ITA's in Pluralistic Society}

The first line of action beneficial for maintaining existing tax ITA's is as obvious as it is non-existent in tax-law making process in Poland. Care for tax ITA's could be shown simply by restraining the pace of introduced changes. As data shows, in 2018 in Poland amendments introduced in tax law regulations run into hundredths, counting 362 pages of typescript of new rules - the highest number since 2004, when it was necessary to replace the Act on Goods and Services Tax and on Excise Tax with new regulation compliant with EU law [Grant Thornton Report 2018: 20]. Less changes mean fewer occasions to disturb existing agreements. The process of refining tax law cannot and should not be stopped, but it is possible to introduce greater extent of "modesty" in this area as well ${ }^{13}$.

Second field of improvement is the connection of introduced changes with daily politics by ruling majority. If the connection is easily perceivable, new regulations not only weaken existing ITA's, but strongly hinder the possibility of arriving at new ones. Poland may be seen as textbook example of group polarization. For more than 15 years polish political scene has been dominated by two parties that do not differ much in terms of political programme. In order to be able to create their own political backgrounds, they had to differ in other fields than substantial proposals. Jointly, they introduced political tactics aimed at creating social divisions by fostering emotional and ideological, yet not substantial differences, to the point in which conflict became permanent. In this situation agreeing upon any concept coming from other side is not possible without being accused of "treason", and the ideas themselves are often only apparent, being put forward in order to imitate goodwill and create new cause for displaying disagreement. It may be said that conflict became a "style" of political practise of these parties [Marzęcki 2012].

In such an environment it is extremely important to try and keep the kind of mid- and low-level regulation which tax law is away from issues at heart of the ongoing political strife. If introduced amendments are seen as connected with political strategy of conflict, they cease to be seen as

13 The pace of changes also causes deterioration of the quality of existing regulations to the point of inducing specific kind of fatalism among the community of tax law users in Poland [Brzeziński 2015: 35-38]. 
substantial changes. Those members of the society that do not ascribe to either side of conflict perceive them only as colourable tools of political strategy, while proponents of both conflicted parties either express unconditional praise or criticism without paying attention to their content.

Without substantial discussion it is impossible to form an ITA. They rely heavily on abandonment of any higher-level theories and ideas (and these are often cited as causes fuelling the conflict in Poland) in order to discuss concrete outcomes of legislative incentives. If proposed provisions are "afflicted" by association with daily politics, their content is obscured by these political higher-level arguments which are as momentous as empty, and which make any agreement unobtainable. The older tax law acts, especially if they are in force since before the polarization took place, if modified often enough in manner allowing to connect the changes with political strategy, are also gradually afflicted.

The avoidance of connection may be achieved in two major spheres. First, and more important, is the substance of introduced amendments. They should be designed with genuine care for tax law efficiency. If tax law is being instrumentalized and treated as a tool for short-lived pursue of votes, there is high risk of its "overuse" which leads to instability, inefficiency, unnecessary limitation of civil liberties and difficulties in application due to excessive complexity and problems with interpretation [Gribnau 2003: 25-26]. It may also lead to deterioration of the quality of tax law and threaten the separation of powers - as Czech example shows [Mrkývka, Czudek 2017: 53; Drywa 2017). These are problems that only add to the fact that changes deepen group polarization and weaken ITA's lying at base of tax law rules ${ }^{14}$.

Second sphere of possible avoidance of connection is the way in which new changes are presented and justified. It they are indeed introduced as parts of political strategy not in tax law interest but the ruling majority, they may be at least disconnected with daily politics in terms of discourse that accompanies their introduction. Tax law, as a whole branch of law from "mid-level" entails vast possibilities of steering the discussion onto substantial, practical and empirical domains. Compliance effects of introduced regulations may be studied and measured. Particular outcomes may be anticipated, and discussed in apolitical "technical" manner.

\footnotetext{
14 The Act on the Solidarity Support Fund for the Disabled which introduced "sympathetic tribute" from the beginning of 2019, that is an income tax calculated from tax base over 1 million PLN at rate of $4 \%$, may be cited as an example. It was introduced as an answer for ongoing protest of the representatives of disabled people that took place in summer of 2018. Along with changes in Act on Personal Income Tax another one was adopted, which introduced new special fund to which the revenue from the tribute was assigned [Act on the Solidarity Support Fund for the Disabled, art. 3 para. 2]. The tribute not only requires high-level type of justification (as socialist in shape), but also breaches buget law principle that forbids to tie particular incomes with particular expenditures.
} 


\section{Conclusion}

Cass Sunstein's idea of incompletely theorized agreements, though in original iteration designed mainly to explain issues of juridical reasoning, was formulated in a way that points at important features of democratic discourse also in the field of law-making. That opens the possibility to juxtapose it onto problems of tax legislative process in Poland and to draw certain conclusions regarding the legislative process in field of taxation. They are as universal, as universal are problems which polish society faces due to its political partition.

In short, the descriptive part of the ITA idea can be summed as a thesis about existence and widespread use of phenomena that enables people to agree on certain outcomes at lower levels of abstraction than possible to cite in discussion regarding problem that needs to be resolved collectively. What stems from that in normative sphere is a prescription of theoretical modesty. It is as an encouragement to focus the discussion around practical outcomes of considered issue and to abstain from using disagreement-entailing, highly theorized, abstractive arguments regarding worldviews and ideas in order to achieve a compromise of possible scope.

The congruence of the idea and empirical reality has to be assessed partly subjectively, as it is justified by rhetorical means. The same logically follows for its normative part.

Tax as such can be seen as institution that lays upon incompletely theorized agreement due to the fact that there are numerous ways in which its existence, shape and according policies may be formed and justified. At the same time, due to its redistributive and ownership-infringing properties it is an institution capable of prompting significant amount of social unrest.

What follows from Sunstein's prescription of theoretical modesty, is that especially in a society in which "group polarization" exists, that is the social conflict is present and profound, tax legislation process should be approached with extreme care. Tax law amendments should be introduced only when necessary and with mitigated frequency. They should as disconnected from political divisions present in the society as possible, not cited as an argument in the row and aimed at improving fiscal effectiveness of whole tax system. Discussion that surrounds their introduction should be as professional, technical and concrete as possible. Only when these conditions are met, the field of tax law and its application bears the chance of being excluded from cross-society conflict, and viceversa should not contribute to its envenoming.

To paraphrase the title of Sunstein's 2001 book: "Keep the political conflict around tax law at bay, and not only legal agreement will follow". 


\section{References:}

Alexander, L.: Incomplete Theorizing: A Review Essay of Cass R. Sunstein's Legal Reasoning and Political Conflict, Notre Dame Law Review, vol. 72 (531), 1997.

Bathaee, Y.: Incompletely Theorized Agreements: An Unworkable Theory of Judicial Modesty, Fordham Urban Law Journal, vol. 34 (5), 2007.

Berlin, I.: The Hedgehog and the Fox, New Jersey: Princeton University Press, 2013.

Brzeziński, B.: Theoretical Perspective in: Nykiel, W., Sęk, M.: Tax Legislation. Standards, Trends and Challenges, Warsaw: Wolters a Kluwer Business, 2015.

Drywa, A.: The Quality of the Tax Law as a Factor Shaping the Taxpayer's Legal Position, in: Radvan, M., Gliniecka, J., Sowiński, T., Mrkývka, P. (eds.): The Financial Law Towards Challenges of the XXI Century, Brno: Publications of the Masaryk University, 2017.

Duxbury, N. Ambition and Adjudication, The University of Toronto Law Journal, vol. 47 (1), 1997

Dworkin, R.: In Praise of Theory, Arizona State Law Journal, vol. 29 (2), 1997.

Dworkin, R.: Justice for Hedgehogs, Cambridge: Harvard University Press, 2011.

George, R., P.: Law, Democracy and Moral Disagreement, Harvard Law Review, vol. 110 (7), 1997.

Gomułowicz, A.: Podatki a etyka [Taxation and Ethics], Warsaw: Wolters Kluwer Poland, 2013.

Goodman, N.: On Starmaking, in: McCormick, P. J. (ed.), Starmaking. Realism, Anti-Realism, Irrealism, Massachusetts: Massachusetts Institute of Technology, 1996.

Goodman, N.: Ways of Worldmaking, Indianapolis: Hackett Publishing Company, 1978.

Grant Thornton Barometer on Stability of Legal Environment in Polish Economy, 2019 Edition, Available at: http://barometrprawa.pl/wpcontent/uploads/2019/02/GrantThornton barometr_prawa_022019.pdf, accessed: $9^{\text {th }}$ June 2020.

Gribnau, J. L. M.,: Equality, Consistency and Impartiality in Tax Legislation, in: Legal Protection Against Discriminatory Tax Legislation. The Struggle for Equality in European Tax Law, The Hague: Kluwer Law International, 2003.

Marzęcki, R., Konstruowanie wzajemnych relacji jako element stylu uprawiania polityki PO i PiS [Building mutual relations as an element of the political style of the Civic Platform (PO) and Law and Justice (PiS) parties], Środkowoeuropejskie Studia Polityczne [Central European Political Studies], vol. 10 (2), 2012. Available at:

https://pressto.amu.edu.pl/index.php/ssp/article/download/10484/10023, accessed: $9^{\text {th }}$ June 2020.

Mrkývka, P., Czudek, D.: Stability and Stabilization of Financial Law, in: Radvan, M., Gliniecka, J., Sowiński, T., Mrkývka, P. (eds.): The Financial Law Towards Challenges of the XXI Century, Brno: Publications of the Masaryk University, 2017

Obuchowski, S.: On Some Assumptions in the Dogmatic Study of Tax Law, Financial Law Review, vol. 3 (1), 2018. Available at: http://www.ejournals.eu/pliki/art/12107/pl, accessed: $9^{\text {th }}$ June 2020.

Obuchowski, S.: Pojęcie zasad prawa w świetle idei pojęć co do istoty kwestionowalnych [The Notion of the 'Principles of Law' in the Light of the Idea of 'Essentially Contested Concepts'], Ruch Prawniczy, Ekonomiczny i Socjologiczny [Journal of Law, Economics and Sociology] vol. 79 (4), 2017. Available at: https://pressto.amu.edu.pl/index.php/rpeis/article/view/11848/11698.

Ostrowski, K.: Prawo finansowe. Zarys ogólny [Financial Law. General Outline], Warsaw: Państwowe Wydawnictwo Naukowe PWN [Polish Scientific Publishers PWN], 1970.

Piotrowska-Marczak, K.: Finance and Financial Law. Relationships and Dependencies, in: Mrkývka, P., Gliniecka, J., Tomášková, E., Juchniewicz, E., Sowiński, T., Radvan, M. (eds.): The Challenges of Local Government Financing in the Light of European Union Regional Policy, Brno: Publications of the Masaryk University, 2018.

Raymond, J. C.: The Methodology of the Humanities, College English, vol. 48 (8), 1982.

Rubin, L.: Legal Reasoning, Legal Process and the Judiciary as an Institution, California Law Review, vol. 85 (1), 1997.

Ruger, J., P.: Health, Health Care, and Incompletely Theorized Agreements: A Normative Theory of Health Policy Decision Making, Journal of Health Politics, Policy and Law, Vol. 32, No. 1, 2007.

Saphiro, S., J.: Fear of Theory, The University of Chicago Law Review, vol. 64 (1), 1997. 
Scholz, J, T.: Trust, Taxes and Compliance, in: Braithwaite, V., Levi, M.: Trust and Governance, New York: Russel Sage Foundation, 1998.

Schroeder, D.: Human Rights and Human Dignity. An Appeal to Separate the Conjoined Twins, Human Rights and Human Dignity, Ethical Theory and Moral Practice, vol. 15 (3), 2012.

Stone, A.: Incomplete Theorizing in the High Court, Federal Law Review, vol. 26 (1), 1998.

Sunstein, C. R., Commentary: Incompletely Theorized Agreements, Harvard Law Review, vol. 108 (7), 1995.

Sunstein, C. R.: Designing Democracy: What Constitutions Do, Oxford: Oxford University Press, 2001.

Sunstein, C. R.: Political Conclict and Legal Agreement, Tanner Lectures on Human Values, available at: https://tannerlectures.utah.edu/documents/a-to-z/s/Sunstein96.pdf, accessed: $9^{\text {th }}$ June 2020.

Sunstein, C., R.: Legal Reasoning and Political Conflict, Oxford: Oxford University Press, 1996.

Verma, N.: Urban Design. An Incompletely Theorized Project, in: Banerjee, T., Loukaitou-Sideris A. (eds.): Companion to Urban Design, New York: Routlege, 2011.

\section{Legal Acts:}

Act of $11^{\text {th }}$ March, 2004 on Goods and Services Tax (consolidated Text Journal of Laws 2020, item 106 as amended).

Act of $23^{\text {rd }}$ October, 2018 on the Solidarity Support Fund for the Disabled (Journal of Laws 2018, item 2192, as amended).

Act of $8^{\text {th }}$ January 1993 on Goods and Services Tax and Excise Tax (Journal of Laws 1993, no. 11, item 50 , as amended). 